Medical Principles and Practice
Med Princ Pract 2017;26:530-534

DOI: $10.1159 / 000485037$
Received: March 7, 2017

Accepted: November 7, 2017

Published online: November 7, 2017

\title{
Mannose-Binding Lectin Does Not Act as a Biomarker for the Progression of Preinvasive Lesions of Invasive Cervical Cancer
}

\author{
Carlos Afonso Maestri ${ }^{a}$ Renato Nisihara ${ }^{c}$ Guilherme P. Ramos ${ }^{b}$ \\ Hellen Weinschutz Mendes ${ }^{c}$ lara Messias-Reason ${ }^{c}$ \\ Newton Sérgio de Carvalho ${ }^{b}$

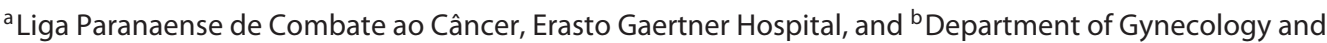 \\ 'Immunopathology Laboratory, Clinical Hospital, Federal University of Parana, Curitiba, Brazil
}

\section{Significance of the Study}

- In this study, mannose-binding lectin (MBL) serum concentrations were not associated with either human papillomavirus infection or cervical carcinogenesis. Hence, the use of MBL serum concentration as a biomarker for the progression of preinvasive cervical lesions into invasive cancer is not recommended.

\section{Keywords}

Complement · Human papillomavirus · Cervical

intraepithelial neoplasia $\cdot$ Cervical cancer

\begin{abstract}
Objective: To evaluate serum concentrations of mannosebinding lectin (MBL) in women presenting with different human papillomavirus (HPV)-associated cervical lesions. Subjects and Methods: A total of 364 women, who underwent screening for cervical cancer or treatment at the Erasto Gaertner Cancer Hospital (HEG), Curitiba, Brazil, were enrolled in the study. Based on the latest cervical colposcopyguided biopsy results, the women were divided into 4 groups: cervical intraepithelial neoplasia CIN-I $(n=54), \mathrm{CIN}-\mathrm{II}$ ( $n=72)$, CIN-III $(n=145)$, and invasive cancer $(n=93)$. A timeresolved immunofluorometric assay was used to measure
\end{abstract}

\section{KARGER}

E-Mail karger@karger.com www.karger.com/mpp

\section{The Author(s) \\ Published by S. Karger AG, Basel \\ Karger \\ Open access}

This is an Open Access article licensed under the Creative Commons Attribution-NonCommercial-4.0 International License (CC BY-NC) (http://www.karger.com/Services/OpenAccessLicense), applicable to the online version of the article only. Usage and distribution for commercial purposes requires written permission. the MBL concentrations in serum. The statistical analysis was done using GraphPad Prism 6.0. Comparisons were performed by Kruskal-Wallis and Mann-Whitney tests and analyzed by $\mathrm{X}^{2}$ test; continuous variables are presented as medians and categorical variables as frequencies. Results: The median MBL concentrations in decreasing order were as follows: invasive cancer: 1,452 ng/mL, CIN-I: 1,324 ng/mL, CINII: 1,104 ng/mL, and CIN-III 1,098 ng/mL. However, no statistical significance was found among the 4 groups with HPVassociated lesions $(p=0.11)$. Equally, the MBL levels did not show a significant association between the age of the patients and the severity of the cervical lesions ( $p=0.68$ ). No statistical significance was found in the median values of $\mathrm{MBL}$ or in the status of $\mathrm{MBL}$ deficient $(<100 \mathrm{ng} / \mathrm{mL})$ and high producers ( $>1,000 \mathrm{ng} / \mathrm{mL}$ ) among the women in each group ( $p=0.77)$. Conclusion: In this study, there was no statistically significant difference in MBL serum levels among the 
groups with CIN. Hence MBL serum concentration appeared not to have influenced the progression of HPV-related preinvasive cervical lesions into invasive cancer.

(c) 2017 The Author(s)

Published by S. Karger AG, Basel

\section{Introduction}

Despite decades of research and preventive effort, cervical cancer remains the second leading cause of cancerrelated death in women worldwide, especially in developing countries [1-3]. The human papillomavirus (HPV) is considered necessary for the development of squamous cell carcinoma of the uterine cervix (SCC) [1]. In about $10 \%$ of women with persistent HPV infection, the development of SCC begins with a preinvasive lesion, known as cervical intraepithelial neoplasia (CIN) $[3,4]$. Based on their capacity to progress into invasive cancer, these preinvasive lesions are classified as follows: high percentage of regression (CIN-I), uncertain behavior (CIN-II), and high potential of progression to cancer (CIN-III).

Cytological screening programs are aimed at detecting and treating these precursor lesions to prevent the onset of invasive cancer [2], but the progression of these preinvasive lesions, most notably high-grade lesions (CIN-II and CINIII), into invasive SCC is still unpredictable [4]. The standard surgical treatments for patients with HPV-associated cervical lesions (especially CIN-II and III) could damage the cervical stroma, leading to cervical stenosis or cervical incompetence $[5,6]$. Therefore, it is crucial to establish methods to identify the patients whose lesions will progress to invasive SCC. Hence, molecular biomarkers which would selectively identify high-risk patients $[2,7]$ have become important tools in the study of cervical cancer.

Mannose-binding lectin (MBL) is used as part of the first line of defense against infection, being a pattern recognition receptor that plays a pivotal role in innate immunity by interacting with surface sugars of a wide variety of microorganisms. The MBL activates the lectincomplement pathway, promotes opsonophagocytosis, and modulates inflammation [8]. Human MBL is encoded by the MBL2 gene, which largely defines MBL serum concentrations because the MBL levels vary 10 -fold among individuals with an identical MBL genotype [911]. Low levels of serum MBL have been reported to be related to vulnerability due to infections by a wide range of microorganisms including viruses $[8,11]$. Conversely, higher levels of MBL could enhance tissue destruction due to unwarranted activation of complement $[8,12]$. In a few studies, an association between HPV and MBL has been reported [13-16]. Two of these studies [14-16] showed that certain polymorphisms in the MBL2 gene were associated with higher susceptibility to infection conferred by high-risk HPV genotypes, but another study [13] did not show any such association between MBL2 polymorphisms and HPV infection.

Ramos et al. [17] have previously reported on MBL concentrations in women presenting with HPV-associated cervical lesions, but there was no statistically significant difference between the median serum MBL levels in HPV-infected women presenting with CIN-III lesions and healthy controls. There are still no reports on MBL concentrations in women presenting with CIN-I and II or invasive cervical cancer. Thus, the objective of the present study was to assess MBL concentrations in HPV-infected women presenting with different cervical lesions.

\section{Subjects and Methods}

The study was carried out at the Erasto Gaertner Cancer Hospital (HEG) in Curitiba, in the southern region of Brazil, a reference center for the treatment of gynecological malignancies. The Institutional Ethics Committee approved the study. Inclusion criteria were cervical cancer screening and treatment at HEG from January 2011 to March 2012. Exclusion criteria were pregnancy, HIV positive, systemic infection, autoimmune disease, and blood transfusion within the last 60 days. Written informed consent was obtained from the all patients.

A group of 364 women was selected for this study. Based on the latest cervical colposcopy-guided biopsy, the 364 women were divided into 4 groups: CIN-I $(n=54)$, CIN-II $(n=72)$, CIN-III $(n=$ $145)$, and invasive cancer $(n=93)$. The loop electrical excision procedure or cold knife cone excision was used to confirm the previous biopsy results. A 3-mL sample of venous blood was collected from each subject and allowed to coagulate; it was then centrifuged and serum was separated, aliquoted $(500 \mu \mathrm{L})$, and stored at $-80^{\circ} \mathrm{C}$ until used to determine MBL concentrations.

\section{MBL Quantification}

An in-house time-resolved immunofluorometric assay, as described by Frederiksen et al. [10], was used to determine the MBL concentration serum samples at Aarhus University, Aarhus, Denmark. Briefly, serum samples were thawed, diluted, and incubated in $1 \mu \mathrm{g}$ mannan-coated wells washed several times. The bound MBL was quantified using biotinylated anti-MBL, followed by europium-labeled streptavidin. An enhancement solution was also added, and the signals were measured by time-resolved fluorometry on a 1232 Delfia fluorometer (Perkin Elmer/Wallac). For each mannan-coated microtiter plate used, 3 standard samples of laboratory controls were added and all the samples and controls were measured in duplicate.

\section{Statistical Analysis}

The statistical analysis was done using GraphPad Prism 6.0 (La Jolla, CA, USA) software package. Comparisons were performed 
Table 1. Patient profile and median values of mannose-binding lectin (MBL) serum concentrations among the 4 groups of human papilloma virus-associated cervical lesions

\begin{tabular}{llllll}
\hline & $\begin{array}{l}\text { CIN-I } \\
(n=54)\end{array}$ & $\begin{array}{l}\text { CIN-II } \\
(n=72)\end{array}$ & $\begin{array}{l}\text { CIN-III } \\
(n=145)\end{array}$ & $\begin{array}{l}\text { SCC } \\
(n=93)\end{array}$ & $p$ value \\
\hline $\begin{array}{l}\text { Age, years } \\
\text { Mean }\end{array}$ & 30.7 & 34.4 & 34.2 & 48.6 & \\
$\begin{array}{l}\text { Range } \\
\text { MBL, ng/mL }\end{array}$ & $15-61$ & $16-73$ & $19-68$ & $21-78$ & 0.1133 \\
$\begin{array}{l}\text { Median } \\
\text { Range }\end{array}$ & 1,324 & 1,104 & 1,098 & 1,452 & \\
\hline
\end{tabular}

CIN-I, II, III, cervical intraepithelial neoplasia, grades 1, 2, and 3; SCC, squamous cell carcinoma of the uterine cervix (cervical cancer).

by Kruskal-Wallis and Mann-Whitney tests and analyzed by $\chi^{2}$ test; continuous variables are presented as medians and categorical variables as frequencies (percentages). Statistical significance was accepted when $p<0.05$.

\section{Results}

The mean age of each of the 4 study groups, the corresponding $\mathrm{MBL}$ serum levels, and lesion severity are shown in Table 1. Based on the median MBL concentration levels, no statistical significance was found among the 4 groups with HPV-associated lesions $(p=0.11)$. Equally, the MBL levels did not show a significant association between the age of the subjects and the severity of the disease $(p=0.68)$.

Of the 364 patients, 19 (5.2\%) presented with MBL levels >5,000 ng/mL: CIN-I: 4 (7.4\%), CIN-II: 2 (2.8\%), CINIII: $3(2.1 \%)$, and SCC: 10 (10.8\%). Of the 10 SCC cases, 1 presented a microinvasive cervical cancer, 2 presented SCC stage I, and the other 7 were advanced SCC.

Based on the serum MBL levels, patients with $\mathrm{MBL}$ concentrations $\leq 100 \mathrm{ng} / \mathrm{mL}$ were considered MBL deficient and those with $>1,000 \mathrm{ng} / \mathrm{mL}$ were considered high producers. The distribution of high and deficient producers among the 4 groups is described in Figure 1. No significant difference was found when comparing the 4 groups according to this distribution $(p=0.77)$.

\section{Discussion}

In the present study, various MBL serum concentrations were not associated with the severity of cervical lesions. Therefore, it is probable that MBL serum concen-

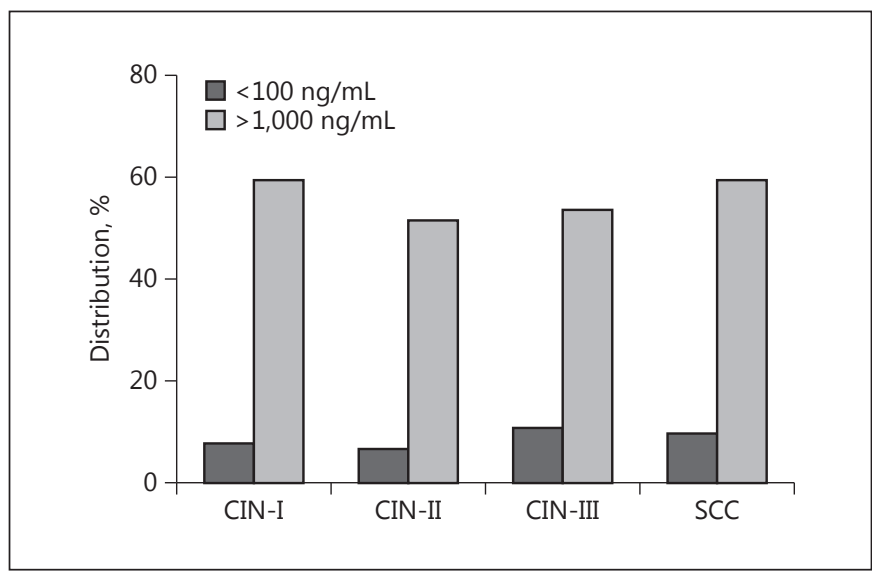

Fig. 1. Distribution of patients of the 4 study groups according to high $(>1,000 \mathrm{ng} / \mathrm{mL})$ and deficient producers $(<100 \mathrm{ng} / \mathrm{mL})$ of mannose-binding lectin. $p=0.774$ ( $\chi^{2}$ test). CIN-I, II, III, cervical intraepithelial neoplasia, grades 1,2 , and 3; SCC, squamous cell carcinoma of the uterine cervix (cervical cancer).

tration did not influence the progression of preinvasive cervical lesions into invasive cancer. The maintenance of stable HPV genomes in cells is the basis for viral deoxyribonucleic acid (DNA) persistence as the primary risk factor in cervical carcinogenesis [3, 4]. As the complement system is part of the innate response, its activation produces inflammation, and it had been reported $[3,4]$ that oncogenesis due to inflammation is associated with cancer development $[3,4]$. However, the mechanisms underlying the relationship between chronic inflammation and cancer still remain undefined.

The innate immune response components plays active roles in the progression of CIN into invasive SCC [7], and it has been shown that immunocompromised patients 
developed more severe HPV infections $[18,19]$. Furthermore, immunodepression has already been associated with increased recurrence of infections and higher viral load as well as the development of precancerous lesions $[7,19]$.

Generally, low levels of MBL concentrations have been associated with vulnerability to bacterial, fungal, and viral infections $[8,20,21]$. Also, it has been suggested to be a potential factor favoring the development of cancer, such as pediatric or solid tumor cancer [22]. Nevadunsky et al. [23] have demonstrated that MBL polymorphism was associated with reduced MBL protein concentrations in the vagina, and that this reduction may increase susceptibility to the development of ovarian cancer.

In this study, deficient and high MBL producers in each group of cervical lesions were indirectly identified by determining the MBL serum concentration. However, no statistically significant difference was found when stratifying the groups regarding MBL production, as previously reported $[15,16]$. Conversely, it has been reported that specific functional polymorphisms in the MBL2 gene could increase women's susceptibility to infection by high-risk HPV genotypes due to low MBL serum levels [14-16]. In addition, Zupin et al. [24] suggested a possible association between $M B L 2$ polymorphisms responsible for low MBL production and susceptibility to the development of atypical squamous cells of undetermined significance.

The virus replicates within the cytoplasm of epithelial cells, preventing the activation of the immune response [25]. In addition, the viral cycle is noncytolytic and occurs only in cells already programmed to die during the epithelial maturation. There are also important viral proteins, E6 and E7, responsible for inactivating the interferon-dependent response, which is responsible for the host's viral protection $[1,26]$. Most importantly, the virus has very low serum circulating levels, avoiding contact with cells and circulating proteins of innate response [25, 26]. Thus, the combination of these mechanisms, most notably the low MBL circulating levels, could explain why variations in the MBL serum concentration have a poor association with HPV infection and associated carcinogenesis.

The current data showed no statistically significant difference between median MBL serum levels of women presenting with CIN-III cervical lesions compared to healthy controls, as previously reported on MBL serum concentrations in HPV-infected women [17].

The SCC group had the highest MBL median concentration and more cases $>5,000 \mathrm{ng} / \mathrm{ml}$. Plausible explanations for this finding could include an increase in $\mathrm{MBL}$ levels secondary to extensive tissue necrosis or metastatic disease leading to a systemic inflammatory process. As MBL is directly involved in the process of apoptosis, the extension of the cervical lesion necrosis itself could potentially interfere with the serum levels [27]. Ytting et al. [28] also reported that an increase in storing and decreased metabolism could be responsible for the higher concentrations and that patients with cancer, most notably colorectal cancer, could present with higher MBL levels regardless of their $M B L 2$ genotype.

\section{Conclusion}

This study did not show any statistically significant difference in the MBL median serum levels among the groups of patients with cervical lesions. Further studies are necessary to identify the role of the complement system in HPV-associated carcinogenesis.

\section{References}

1 Bosch FX, Broker TR, Forman D, et al: Comprehensive control of human papillomavirus infections and related diseases. Vaccine 2013; 31:H1-H31.

2 Arbyn M, Castellsagué X, de Sanjosé S, et al: Worldwide burden of cervical cancer in 2008. Ann Oncol 2011;22:2675-2686.

3 Van Doorslaer K, Burk RD: Evolution of human papillomavirus carcinogenicity. Adv Virus Res 2010;77:41-62.

4 Woodman CB, Collins S, Winter H, et al: Natural history of cervical human papillomavirus infection in young women: a longitudinal study. Lancet 2001;357:1831-1836.
5 Arbyn M, Kyrgiou M, Simoens C, et al: Perinatal mortality and other severe adverse pregnancy outcomes associated with treatment of cervical intraepithelial neoplasia: a metaanalysis. BMJ 2008;337:a1284.

6 Kyrgiou M, Athanasiou A, Paraskevaidi M, et al: Adverse obstetric outcomes after local treatment for cervical preinvasive and early invasive disease according to cone depth: systematic review and meta-analysis. BMJ 2016; 354:i3633.
7 Kadish AS, Timmins P, Wang Y, et al: Regression of cervical intraepithelial neoplasia and loss of human papillomavirus (HPV) infection is associated with cell-mediated immune responses to an HPV type $16 \mathrm{E} 7$ peptide. Cancer Epidemiol Biomarkers Prev 2002;11:483488.

8 Turner MW: The role of mannose-binding lectin in health and disease. Mol Immunol 2003;40:423-429.

9 Garred P, Larsen F, Madsen HO, et al: Mannose binding lectin deficiency. Mol Immunol 2003;40:73-84. 
10 Frederiksen, PD, Thiel S, Jensen L, et al: Quantification of mannan-binding lectin. J Immunol Methods 2006;315:49-60.

11 Heitzeneder S, Seidel M, Förster-Waldl E, et al: Mannan-binding lectin deficiency - good news, bad news, doesn't matter? Clin Immunol 2012;143:22-38.

12 Schafranski MD, Stier A, Nisihara R, et al: Significantly increased levels of mannose-binding lectin (MBL) in rheumatic heart disease: a beneficial role for MBL deficiency. Clin Exp Immunol 2004;13:521-525.

13 Parrella P, Seripa D, Matera MG, et al: Lack of association between genetic variants in the mannose-binding lectin 2 (MBL2) gene and HPV infection. Eur J Epidemiol 2007;22:159162.

14 Guimaraes V, Guimaraes R, Brandao L, et al. Association between MBL2 gene functional polymorphisms and high-risk human papillomavirus infection in Brazilian women. Hum Immunol 2008;69:273-278.

15 Tsai CC, Lin TM, You HL, et al: Mannosebinding lectin in high-risk human papillomavirus infection. Am J Obstet Gynecol 2009; 200:618.e1-e6.

16 Segat l, Crovella S, Comar M, et al: MBL2 gene polymorphisms are correlated with high-risk human papillomavirus infection but not with human papillomavirus-related cervical cancer. Hum Immunol 2009;70:436-439.
17 Ramos GP, Nisihara R, Maestri CA, et al: MBL serum concentration in women with HPV presenting CIN III lesions. Hum Immunol 2013;74:67-69.

18 Clifford GM, Polesel J, Rickenbach M, et al: Cancer risk in the Swiss HIV Cohort Study: associations with immunodeficiency, smoking, and highly active antiretroviral therapy. J Nat Cancer Inst 2005;97:425-432.

19 Palefsky JM: Anal cancer prevention in HIVpositive men and women. Curr Opin Oncol 2009;21:433-438.

20 Donders GG, Babula O, Bellen G, et al: Mannose-binding lectin gene polymorphism and resistance to therapy in women with recurrent vulvovaginal candidiasis. BJOG 2008; 115:1225-1231.

21 Ip WK, To YF, Cheng SK, et al: Serum mannose-binding lectin levels and MBL2 gene polymorphisms in different age and gender groups of southern Chinese adults. Scand J Immunol 2004;59:310-314.

22 Frakking FN, Brouwer N, Dolman KM, et al: Mannose-binding lectin (MBL) as prognostic factor in paediatric oncology patients. Clin Exp Immunol 2011;165:51-59.
23 Nevadunsky NS, Korneeva I, Caputo T, et al: Mannose-binding lectin codon 54 genetic polymorphism and vaginal protein levels in women with gynecologic malignancies. Eur J Obstet Gynecol Reprod Biol 2012;163:216218.

24 Zupin L, Polesello V,Casalicchio G, et al: MBL2 polymorphisms in women with atypical squamous cells of undetermined significance. J Med Virol 2015;18:851-859.

25 Stanley M: HPV - immune response to infection and vaccination. Infect Agent Cancer 2010;20:5-19.

26 Pett MR, Herdman MT, Palmer RD, et al: Selection of cervical keratinocytes containing integrated HPV16 associates with episome loss and an endogenous antiviral response. Proc Natl Acad Sci USA 2006;103:3822-3827.

27 Nauta AJ, Raaschou-Jensen N, Roos A, et al: Mannose-binding lectin engagement with late apoptotic and necrotic cells. Eur J Immunol 2003;33:2853-2863.

28 Ytting H, Christensen IJ, Steffensen R, et al: Mannan-binding lectin (MBL) and MBL-associated serine protease 2 (MASP-2) genotypes in colorectal cancer. Scand J Immunol 2011;73:122-127. 